\title{
Brief
}

\section{Relation of waveform of transit-time flow measurement and graft patency in coronary artery bypass grafting}

\author{
Atsutoshi Hatada, MD, ${ }^{a}$ Tatsuya Yoshimasu, MD, PhD, ${ }^{a}$ Masahiro Kaneko, MD, ${ }^{a}$ Mitsumasa Kawago, MD, ${ }^{a}$ \\ Mitsuru Yuzaki, MD, ${ }^{a}$ Kentaro Honda, MD, ${ }^{a}$ Shigeru Komori, MD, ${ }^{a}$ Masahiro Iwahashi, MD, ${ }^{a}$ Hiroki Hayashi, MD, \\ Shuji Yamamoto, MD, ${ }^{c}$ Yoshiharu Nishimura, MD, PhD, ${ }^{a}$ Takeshi Hiramatsu, MD, PhD, ${ }^{a}$ and \\ Yoshitaka Okamura, MD, PhD, ' Wakayama, Japan
}

From the Department of Thoracic and Cardiovascular Surgery, a Wakayama Medical University School of Medicine; Department of Thoracic and Cardiovascular Surgery, ${ }^{\mathrm{b}}$ Minami Wakayama Medical Center; and Department of Cardiovascular Surgery, ${ }^{c}$ Hashimoto Municipal Hospital, Wakayama, Japan.

Received for publication March 22, 2007; accepted for publication April 19, 2007.

Address for reprints: Atsutoshi Hatada, MD, Department of Thoracic and Cardiovascular Surgery, Wakayama Medical University School of Medicine, 811-1 Kimiidera, Wakayama 641-8509, Japan (E-mail: hatada@mail.wakayama-med.ac.jp).

J Thorac Cardiovasc Surg 2007;134:789-91

$0022-5223 / \$ 32.00$

Copyright @ 2007 by The American Association for Thoracic Surgery

doi:10.1016/j.jtcvs.2007.04.054

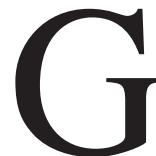
raft patency is the major factor limiting the initial clinical benefits of revascularization and patient survival; however, it is not easy to anticipate. Transit-time flow measurement (TTFM) has been the common method of assessing intraoperative coronary artery bypass grafting (CABG) patency because it is a noninvasive and easy method. TTFM provides a mean graft flow (MGF), a flow waveform, and derived values such as the pulsatility index (PI). D'Ancona and colleagues ${ }^{1}$ reported the necessity to revise $3 \%$ of grafts on the basis of TTFM and emphasized the crucial feature of flow value interpretation as an index of graft patency. Takami and $\mathrm{Ina}^{2}$ reported the relation between the graft flow waveform and the anastomotic quality of CABG using a fast Fourier transformation (FFT) analysis. However, there have been no reports that graft patency can be anticipated using analysis of the graft flow waveform.

We demonstrate that graft patency can be assessed with FFT analysis of TTFM waveform.

\section{Clinical Summary}

The present study included 29 patients who underwent isolated CABG with cardiopulmonary bypass and a postoperative cardiac catheterization (the term after CABG; 3-6 months). The patients received 29 saphenous vein grafts, all aortocoronary bypass grafts, including 24 patent grafts in the future and 5 occluded grafts. All anastomoses were performed by 1 surgeon (Y. O.) in the same fashion.

Graft flow tracing was obtained intraoperatively using a transit-time flowmeter (BF 1000; Medi-Stim AS, Oslo, Norway). A flow probe to fit each saphenous vein graft (3-4 mm) was placed around the graft when hemodynamic conditions were stable after weaning from CABG. On the basis of the obtained flow profile, the following variables were calculated: MGF, PI, and FFT of the flow waveform. Harmonics of FFT analysis by the flowmeter existed at frequencies that were multiplies of the frequency of the original waveform and were described in terms of an amplitude and a phase. In the present study, we defined $\mathrm{F}_{0}$ as a power of the fundamental frequency, $\mathrm{H}_{1}$ as a power of the first harmonic, $\mathrm{H}_{2}$ as a power of the second harmonic, and sequentially as $\mathrm{H}_{3}, \mathrm{H}_{4}, \mathrm{H}_{5}, \mathrm{H}_{6}, \mathrm{H}_{7}, \mathrm{H}_{8}, \mathrm{H}_{9}$, and $\mathrm{H}_{10}$. $\mathrm{Ha}\left(=\mathrm{H}_{5}+\mathrm{H}_{6}\right.$ $+\mathrm{H}_{7}+\mathrm{H}_{8}+\mathrm{H}_{9}+\mathrm{H}_{10}$ ) was calculated.

All data were expressed as mean \pm standard division. Comparison of the data between the patent and occluded grafts was performed using the Student $t$ test.

\section{Results}

Figure 1 shows the PI and MGF of each group (patent grafts and occluded grafts). There was no significant difference between the patent grafts and occluded grafts (PI: $27.2 \pm 16.6$ vs $21.0 \pm 10.9$, respectively, $P=.181$; MGF: $3.60 \pm 2.23$ vs $4.91 \pm 4.69$, respectively, $P=$ .155). Figure 2 shows the power of $\mathrm{Ha}$. In the spectrum from $\mathrm{H}_{5}$ to $\mathrm{H}_{10}$, the power in the group of patent grafts was significantly higher than that in the group of occluded grafts. Ha in the group of patent grafts was significantly higher than that in the group of occluded grafts $(0.352 \pm 0.0517$ vs $0.485 \pm 0.402$, respectively, $P=.04)$. 

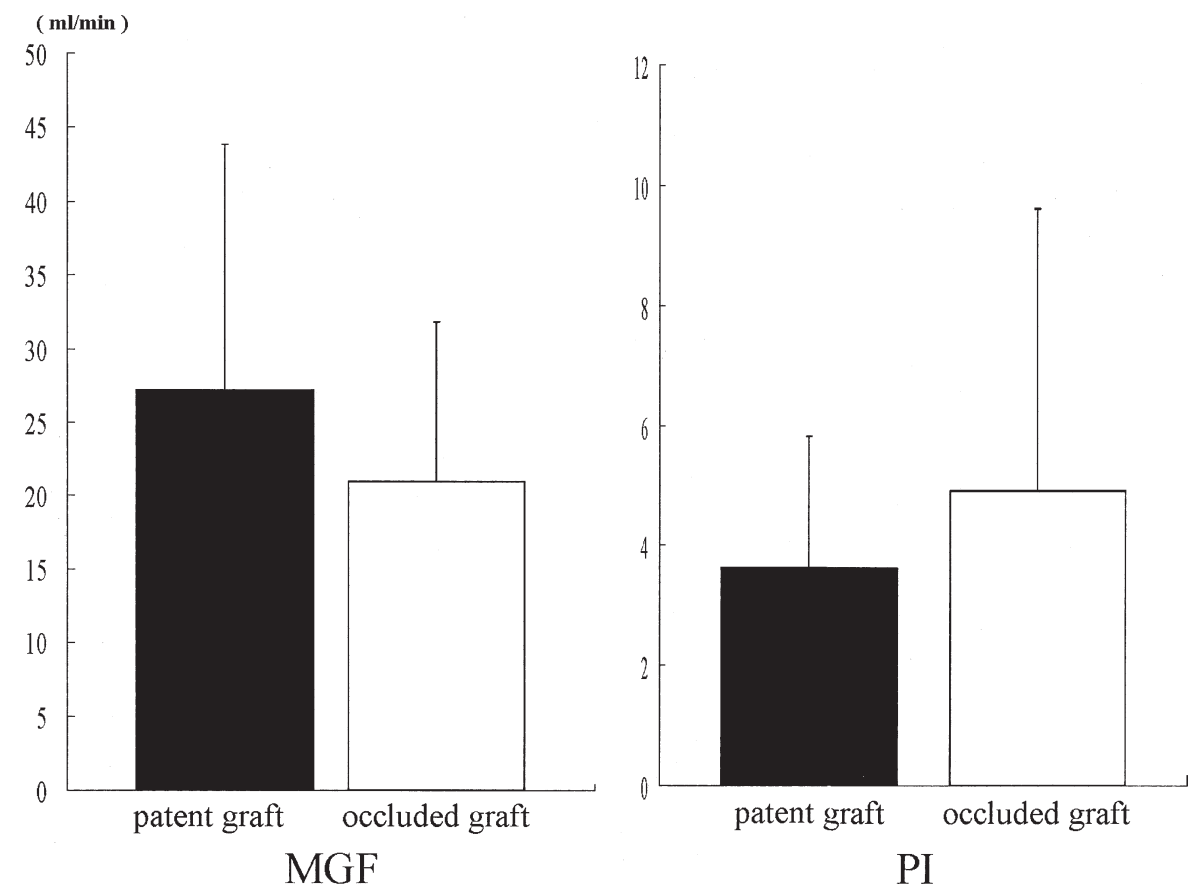

Figure 1. Comparison of PI and MGF between patent and nonpatent grafts. Bars show mean \pm SD. PI, Pulsatility index; $M G F$, mean graft flow.

\section{Discussion}

D'Ancona and colleagues ${ }^{1}$ emphasized the reliance on correct analysis of TTFM flow patterns to correct abnormalities and reported a predominantly systolic flow in 34 of 37 grafts, which had altered to a diastolic pattern after revision. The flow pattern was useful to confirm graft patency in conjunction with adequate MGF and PI values. In this study, MGF and PI values were not significantly different between the patent grafts and the nonpatent grafts. Some reports ${ }^{3,4}$ demonstrated that graft flow waveform was more important in relation to graft patency than graft flow volume, because graft flow waveform affects the perfusion area of target vessels, coronary resistance, graft resistance, and quality of anas-

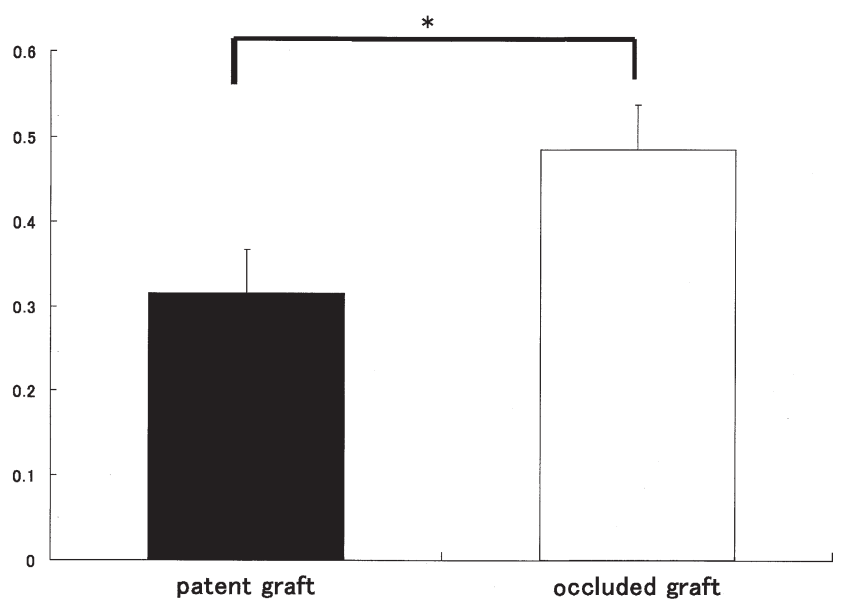

Figure 2. Comparison of Ha between patent and nonpatent grafts. Bars show mean \pm SD. ${ }^{*} P=.04$. tomosis. We did not consider the quality of anastomosis because our study did not include the grafts with anastomotic stenosis.

In contrast, although it was reported that the diastolic filling pattern was a good graft flow waveform, ${ }^{5}$ no study has reported that pattern expressed as the numeric value. We demonstrated graft flow waveform expressed as the numeric value using FFT analysis, and harmonics of FFT analysis may become the parameter to express graft patency when comparing patent grafts with nonpatent grafts.

We did not report the cutoff value of the parameter including $\mathrm{H}_{5}$, $\mathrm{H}_{6}, \mathrm{H}_{7}, \mathrm{H}_{8}, \mathrm{H}_{9}, \mathrm{H}_{10}$, and Ha. Because the graft flow waveform was different in each kind of graft, including the internal thoracic artery, gastroepiploic artery, radial artery, and saphenous vein, we should investigate the parameters in each kind of graft in the future.

\section{Conclusions}

We demonstrated that graft patency may be anticipated using FFT analysis of TTFM waveform.

We acknowledge the technical assistance of Ryota Tsubaki, a graduate student of Kobe University.

\section{References}

1. D'Ancona G, Karamanoukian HL, Ricci M, Schmid S, Bergsland J, Salerno TA. Graft revision after transit time flow measurement in off-pump coronary artery bypass grafting. Eur J Cardiothorac Surg. 2000;17:287-93.

2. Takami Y, Ina H. Relation of intraoperative flow measurement with postoperative quantitative angiographic assessment of coronary artery bypass grafting. Ann Thorac Surg. 2001;72:1270-4.

3. Grines CL, Watkins MW, Helmer G, Penny W, Brinker J, Marmur JD, et al. Angiogenic gene therapy (AGENT) trial in patients with stable angina pectoris. Circulation. 2002;105:1291-7. 
4. Hagiwara H, Shirakawa M, Nakayama T, Asai T, Nakayama M, Ito T, et al. The correlation between flow pattern during cardiopulmonary bypass and patency of the coronary artery bypass grafts. Kyobu Geka. $2005 ; 58: 519-23$
5. Morota T, Duhaylongsod FG, Burfeind WR, Huang T. Intraoperative evaluation of coronary anastomosis by transit-time ultrasonic flow measurement. Ann Thorac Surg. 2002;73:144650 .

\title{
Intermittent incomplete closure of Medtronic Advantage aortic valve leaflets causes unnecessary reoperation
}

\author{
Rune Haaverstad, MD, PhD, ${ }^{\mathrm{a}, \mathrm{c}}$ Nicola Vitale, MD, PhD, ${ }^{\mathrm{a}, \mathrm{c}}$ Arve Tromsdal, MD, ${ }^{\mathrm{a}, \mathrm{b}}$ Knut Hegbom, MD, ${ }^{\mathrm{b}}$ and \\ Asbjørn Karevold, MD, ${ }^{a}$ Trondheim, Norway
}

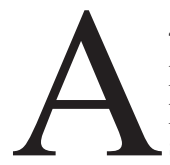

40-year-old man underwent isolated aortic valve replacement with a 23-mm Medtronic Advantage valve prosthesis (Medtronic, Minneapolis, Minn) for severe stenosis of a bicuspid aortic valve. The valve was implanted with pledgets by the non-everting suture technique and placed with the central orifice pointing in between the coronary ostia. The postoperative course was uneventful, and the patient was discharged on the sixth postoperative day. Control transthoracic echocardiograms were performed before discharge and 6 and 12 months after discharge, all of which showed a normal functioning prosthetic valve with a mean gradient of $12 \mathrm{~mm} \mathrm{Hg}$. The patient was in New York Heart Association functional class I and had resumed all his activities within the follow-up.

\section{Clinical Summary}

Two years after surgery and 1 year after the last echocardiogram, the patient had occasional transient memory losses and disturbed vision, which were consistent with thromboembolism because they were associated with a nontherapeutic international normalized ratio (INR) of 1.3. The patient underwent hemorrhoid surgery during the same period, which contributed to keep the INR level well below the desired 2.5 to 3.5 range. At the routine 2-year follow-up control (25.5 months after valve implantation), the patient was in good health and asymptomatic, despite a diastolic murmur of variable intensity on auscultation. The transthoracic echocardiogram revealed an intermittent and incomplete closure of the prosthetic leaflet, causing single-beat valve regurgitation of a degree varying from $1+$ to $3+$. The mean transvalvular

From the Departments of Cardiothoracic Surgery ${ }^{\mathrm{a}}$ and Cardiology, ${ }^{\mathrm{b}} \mathrm{St}$ Olavs University Hospital, Trondheim, Norway; and Institute of Circulation and Medical Imaging, ${ }^{\mathrm{c}}$ Norwegian University of Science and Technology, Trondheim, Norway.

Received for publication April 8, 2007; accepted for publication April 20, 2007.

Address for reprints: Rune Haaverstad, MD, PhD, Department of Cardiothoracic Surgery, St Olavs University Hospital, N 7018 Trondheim, Norway (E-mail: rune.haaverstad@ntnu.no).

J Thorac Cardiovasc Surg 2007;134:791-2

$0022-5223 / \$ 32.00$

Copyright $\odot 2007$ by The American Association for Thoracic Surgery doi:10.1016/j.jtcvs.2007.04.055 gradient was $14 \mathrm{~mm} \mathrm{Hg}$. The transesophageal echocardiogram confirmed these findings. The patient then underwent fluoroscopy; during the investigation the patient was in sinus rhythm, as usual, and no ectopic ventricular beats were recorded. Fluoroscopy showed intermittent incomplete closure of both valve leaflets (Figure 1). An incomplete closure of the anterior leaflet occurred approximately every 10 beats; this appeared to create a minor gap between the inner side of the ring and the leaflet edge, most likely causing a trivial regurgitation (Figure $1, A$ ). In addition, a closure delay of the posterior leaflet was caught just once during film recording. In this position, it was discovered that the posterior leaflet stood open at approximately 90 degrees from the valve ring while the anterior leaflet was closed (Figure 1, $B$ ). We believe this phenomenon is responsible for the $3+$ regurgitation noted on the echocardiograms.

On the basis of the patient history and investigations, the cause of the prosthetic malfunction was assumed to be an obstruction limiting leaflet excursions; therefore, the patient underwent reoperation the following day. During surgical exploration, no pannus or thrombus was found on or around the valve; the valve was normal in appearance and function, and both leaflets had free movement. No subvalvular tissue was seen bulging into the hinge mechanism, and the valve was left in place.

The postoperative course was uneventful, and the patient was discharged. At the last control in March 2007, the patient was still in New York Heart Association class I and totally asymptomatic; his INR level was stable between 2.5 and 3.5. The transthoracic echocardiography showed a mean gradient of $12 \mathrm{~mm} \mathrm{Hg}$ and an intermittent incomplete closure of 1 leaflet in approximately $15 \%$ of the strokes, determining transient, single-beat, trivial-to-mild regurgitation.

\section{Discussion}

This case report is in line with previous articles from Munich in which a total of 7 cases of intermittent regurgitation of a Medtronic Advantage aortic valve were observed. ${ }^{1,2}$ Unfortunately, in our case there were several confounding factors that led us to believe the incomplete closure was caused by a thrombotic obstruction, and the patient underwent reoperation. First, there was a transient ischemic attack associated with a prolonged period of a low INR level, which was then followed by concomitant recent hemorrhoid 